\title{
Penerapan Teknologi Informasi di Industri Farmasi
}

\author{
Esni Esni \\ Program Magister Farmasi, Fakultas Farmasi, Universitas Padjadjaran, Sumedang, 45363 \\ email: eznyheadgear@gmail.com
}

\section{Abstrak :}

Industri farmasi Indonesia tentu tidak dapat mengisolasi diri dari perkembangan dan persaingan regional maupun global. Tantangan dan permasalahan yang dihadapi oleh industri farmasi akan semakin kompleks. Sehingga peran teknologi informasi bagi industri farmasi sangatlah penting dan tentu saja memiliki tujuan yang beragam tak terkecuali untuk mendukung kepentingan usahanya. Dalam review artikel ini akan dibahas terkait penerapan teknologi informasi di industri farmasi saat ini.

Keyword : teknologi informasi, industri farmasi

\section{Pendahuluan}

Sistem informasi sendiri adalah susunan atau kumpulan dari data, proses, penyajian informasi, dan teknologi informasi yang seluruhnya berinteraksi untuk mengembangkan pengoperasian sehingga dapat menyelesaikan masalah dan membuat keputusan yang dibutuhkan oleh sebuah organisasi, managemen dan user.

Seiring dengan perkembangan zaman dan kemajuan teknologi, seluruh kegiatan yang berhubungan dengan manusia di tuntut untuk lebih inovatif dan advance. Dalam hal ini tak terkecuali industri farmasi.

Industri Farmasi adalah badan usaha yang memiliki izin dari Menteri Kesehatan untuk melakukan kegiatan pembuatan obat atau bahan obat.

Dalam pelaksanaan membuat obat atau bahan obat tentu saja harus dibarengi dengan teknologi yang menunjang, mulai dari awal mula yakni bahan baku dan bahan kemas hingga dapat release dan mendapat predikat finish good. Untuk dikatakan suatu produk telah memenuhi spesifikasi harus melalu beragam proses yang ditangani oleh berbagai divisi di industri farmasi.

\section{Cara Pembuatan Obat yang Baik}

Indonesia sendiri memiliki pedoman dalam pembuatan obat jadi yang dikenal dengan CPOB. Cara Pembuatan Obat yang Baik (CPOB) merupakan pedoman yang harus diterapkan dalam seluruh rangkaian proses di industri farmasi dalam pembuatan obat jadi, sesuai dengan keputusan Menteri Kesehatan RI No.43/Menkes/SK/II/1988 tentang Cara Pembuatan Obat yang Baik.

Pedoman CPOB bertujuan untuk menjamin obat dibuat secara konsisten, memenuhi persyaratan yang ditetapkan dan sesuai dengan tujuan penggunaanya. 
CPOB mencakup seluruh aspek produksi dan pengendalian mutu. Pada proses pembuatan obat, pengendalian menyeluruh menjadi sangat wajib untuk menjamin bahwa obat yang bermutu tinggi tidaklah cukup bila produk jadi hanya sekedar lulus dari serangkaian pengujian, tetapi yang lebih penting adalah bahwa mutu harus dibentuk ke dalam produk tersebut (to build quality into the product).

Mutu obat tergantung pada bahan awal, bahan pengemas, proses produksi, pengendalian mutu, bangunan, peralatan yang dipakai, serta personel yang terlibat. Oleh sebab itu, Pemastian Mutu suatu obat hendaknya dibuat dalam kondisi yang dikendalikan dan dipantau secara cermat.

\section{Penerapan Teknologi dalam CPOB}

Dalam CPOB juga telah menggambarkan beberapa teknologi yang dapat menunjang dan digunakan di industri farmasi. Lebih tepatnya pada CPOB aneks 1 mengenai pembuatan produk steril yang tidak hanya membahas tentang klasifikasi dan pemantauan ruang bersih dan sarana udara bersih tetapi juga mengenai teknologi isolator, teknologi peniupan/pengisian/penyegelan, produk yang mengalami sterilisasi akhir, pembuatan secara aseptis dan sebagainya. Serta dokumentasi yang merupakan suatu tindakan untuk menyediakan dokumen-dokumen berupa keterangan dan penerangan pengetahuan dan bukti yang akurat sebagai sumber informasi khusus dengan menggunakan teknologi tekini dalam industri farmasi.

\section{TEKNOLOGI ISOLATOR}

Penggunaan teknologi isolator bertujuan secara kecenderungan untuk memperkecil resiko pencemaran mikroba oleh manusia dan lingkungan secara signifikan terhadap produk yang akan dibuat secara aseptis.

Isolator dan lingkungan sekitarnya hendaklah didesain sedemikian rupa sehingga mutu udara yang dipersyaratkan untuk zona tersebut dapat dicapai. Isolator dibuat dari berbagai bahan yang tahan terhadap tusukan dan kebocoran. Alat transfer bervariasi dari desain satu pintu, dua pintu sampai ke sistem tertutup secara sempurna yang disatukan dengan mekanisme sterilisasi.

Untuk transfer bahan ke dalam dan ke luar unit merupakan sumber kontaminasi yang paling potensial. Secara umum, area di dalam isolator merupakan zona lokal untuk melakukan manipulasi yang berisiko tinggi, meskipun laminar air flow bisa tidak ada di area kerja ini. Kelas udara yang diperlukan untuk lingkungan latar belakang tergantung pada desain isolator tersebut serta penggunaannya. Hal tersebut hendaklah dikendalikan dan untuk proses aseptis setidaknya Kelas D.

Isolator dapat diterapkan setelah dilakukan validasi sesuai prosedur termasuk mempertimbangkan faktor kritis dari teknologi isolator misal mutu udara di dalam dan di luar (latar belakang) isolator, sanitasi isolator, proses transfer dan kekedapan isolator. Selain itu, pemantauan harus dilakukan secara rutin dan mencakup uji kebocoran isolator dan sistem sarung tangan/lengan yang sering.

\section{TEKNOLOGI PENIUPAN/PENGISIAN/ PENYEGELAN}

Mesin peniup/pengisi/penyegel merupakan satu rangkaian mesin dimana dalam sistem operasi yang kontinu, wadah produk akan dibentuk dari granulat termoplastis, diisi dan kemudian disegel. Semua ini dilakukan oleh satu unit mesin otomatis. 
Umumnya digunakan untuk produksi aseptis yang dilengkapi dengan air shower yang efektivitasnya sama dengan Kelas A serta dapat dipasang dalam lingkungan minimal Kelas $C$, dengan syarat mengenakan pakaian kerja Kelas A/B. Mesin yang digunakan untuk pembuatan produk dengan sterilisasi akhir hendaklah dipasang dalam lingkungan minimal Kelas $D$.

Area lingkungan kerja diharapkan memenuhi persyaratan jumlah partikel dan mikroba pada kondisi "nonoperasional" dan persyaratan jumlah mikroba hanya pada saat beroperasi.

Beberapa hal yang perlu dipertimbangkan terkait teknologi khusus ini yaitu:

desain dan kualifikasi peralatan,

validasi dan reprodusibilitas dari pembersihan-di-tempat dan sterilisasi-di-tempat, tingkat kebersihan lingkungan latar belakang di mana peralatan tersebut ditempatkan, pelatihan dan pakaian kerja operator, serta intervensi terhadap zona kritis mesin termasuk proses perakitan aseptis sebelum memulai proses pengisian.

\section{Dokumentasi}

Spesifikasi (bahan awal, bahan pengemas primer, produk antara, produk ruahan dan produk jadi), prosedur pengolahan induk dan prosedur pengemasan induk hendaklah komprehensif sesuai dengan perkembangan ilmu pengetahuan mutakhir.

Dokumen tersebut hendaklah dikaji ulang secara berkala selama pengembangan dan dimutakhirkan sesuai kebutuhan. Tiap versi baru hendaklah memerhatikan data terakhir, teknologi terkini yang digunakan, peraturan dan persyaratan farmakope, serta hendaklah memudahkan ketertelusuran dokumen sebelumnya. Tiap perubahan hendaklah dilakukan sesuai prosedur tertulis, dengan memerhatikan implikasi terhadap mutu produk seperti stabilitas dan bioekivalensi.

\section{SAP (System Analysis And Program)}

SAP (System Analysis And Program) merupakan salah satu software ERP (Enterprise Resource Planning) yang saat ini telah di aplikasikan dibeberapa perusahaan di dunia. Negara indonesia telah menerapkan SAP pada perusahaan atau industri farmasi kelas atas dan menengah dalam proses managementnya. Dalam segi finansial SAP diketahui mencapai puluhan juta rupiah.

SAP dianggap sebagai suatu karya kemajuan teknologi yang dirancang dan berperan untuk memudahkan dalam proses managemen. Kelebihan lain dari SAP adalah software Entreprise yangmana costum dapat dirancang sesuai dengan kehendak user. Diketahui ada beberapa bentuk modul dalam SAP yaitu:

- Modul Finance (FI)

- Modul Controlling (CO)

- Modul Material Management (MM)

- Modul Quality Management (QM)

- Human Capital Management (HCM)

- Production Planning (PP)

- Plant Maintenance (PM)

- Project System (PS)

- Sales Distribution (SD) 
Tahapan dalam pengoperasian SAP yaitu di awali dengan login sampai pada tahap operasional dalam produksi (mencakup tahapan pembuatan obat, material request dan perencanaan produksi). Central dari aplikasi SAP adalah master data yang selalu difungsikan dalam sebagian besar transaksi. Transaksi tersebut dapat berupa permintaan aktif ingredient dan bahan tambahan ke pihak warehouse yang nantinya akan dibuat master data.

\section{Daftar pustaka :}

Badan POM., 2012., Pedoman Cara Pembuatan Obat Yang Baik. Jakarta: Badan Pengawas Obat dan Makanan RI

McLeod. 2004. Sistem Informasi Manajemen. PT. Indeks. Jakarta.

Mubarok, F., 2016., SAP dalam Perusahaan Farmasi., http://farmasiindustri.com/tag/sap

Sampurno., 2007., Kapabilitas teknologi dan penguatan R\&D: tantangan industri farmasi Indonesia., majalah Farmasi Indonesia., Yogyakarta. 